\title{
Study on Cultural Governance of Cross-Border Ethnic Areas
}

\section{Based on the Investigation and Analysis of Cultural Exchanges in Dehong Prefecture, Yunnan Province}

\author{
Mou Jun \\ School of Finance and Public Manegement, Yunnan \\ University of Finance and Economics, Kunming, P. R. China, \\ 650221 \\ moujun77zz@163.com
}

\author{
Li Qin \\ School of International Languages and Cultures, Yunnan \\ University of Finance and Economics \\ Kunming, P.R. China, 650221 \\ liqin01@189.cn
}

\begin{abstract}
- "cultural governance" is an academic category that has arisen in recent years. It is undoubtedly of great theoretical value and practical significance to understand and analyze the characteristics of Chinese society through the field of cultural governance. This paper focuses on the foreign cultural exchange activities in Dehong prefecture , Yunnan province and tries to explore and reflect on the practices of "cultural governance" in Yunnan province, aiming at the behaviors of countries and governments in the cultural field.
\end{abstract}

Keywords—cross-border ethnic areas, cultural governance, Dehong prefecture, foreign cultural exchanges

\section{INTRODUCTION}

"Culture governance" is an academic category that has emerged in recent years, and how they should be defined is still in a stage of discussion, reflection and further understanding through practice.

It is generally accepted that "cultural governance" comes from Fuke's concept of "Rationalism", but there is a great diversity in understanding of cultural governance. In the European and American academic circles, the concept of "cultural governance" was first proposed and discussed by Tony Bennett. However, his own use of the term "cultural governance" was very vague., most of which was to separate the culture from the governing reason. For example, he defined the cultural circle as "we must regard culture as the historical condition inlayed in governance relations. The expanding population can be properly managed through technology, aesthetics and the polity of intellectual culture. Therefore, such process is considered as" the governance of social life ". In the latter part of the study, Bennett also regards culture as a governance mechanism that plays a role in social relations. Therefore, although the western scholars like Benny are concerned about the issue of culture and governance, "cultural governance" has not been put forward and systematically discussed in their works as a core concept. In this aspect, Chinese scholars in Taiwan stand in the front ranks. The academic circle in Taiwan is mainly influenced by Wang Zhihong's concept of cultural governance. Wang Zhihong puts forward and theorizes the concept of cultural governance in the "Chinese context". What he has defined on "the fundamental meaning of the concept of cultural governance is to see it as the field of culture and politics, namely the power operation 
and resource allocation mechanism through representation, symbol and ideation, as well as the institutional mechanism of understanding the world and self-knowledge".

In the 21 st century, influenced by western theories, Chinese scholars have also joined in the discussion of cultural governance. In particular, the Third Plenum of the 18th CPC Central Committee put forward the general objective of deepening reform, which means "promoting the modernization of national governance system and governance capability". Centering on the concept of "national governance system", some scholars pointed out that "national governance system includes various forms of governance, such as politics, economy and culture". They believed that "cultural governance" is a form of governance that is "more fundamental, broader and more profound" in the national governance system, which is interrelated and interactive with other forms of governance.

Although scholars make much concerns over the problem of social governance in cross-border ethnic areas, it does not carry out systematic discussions on "cultural governance" as the core concept. For example, $\mathrm{Xu}$ Mingzhe points out cross-border ethnic groups are utterly ignorant in ethnic identity and state identity, which is an obvious phenomenon. Therefore, how to correctly deal with ethnic identity and state identity of cross-border ethnic groups and make them no longer hesitate between the choice of ethnic identity and state identity can directly affects the status and development of the whole cross-border ethnic groups in the sovereign state. It is clear that the study of the cultural governance of cross-border ethnic groups is important for the ethnic identity and state identity of the people across border.

Is cultural governance a theoretical concept worthy of further discussion or merely an analytical tool? It is still uncertain in theory and academic circles. However, undoubtedly it has a strong theoretical value and realistic significance if we can put a high focus on current cultural governance activities through the cultural governance field to understand and analyze the characteristics of today's society in China. This paper focuses on the foreign cultural exchange activities in Dehong prefecture, Yunnan province, and tries to explore and reflect on the practices of "cultural governance" in
Yunnan province, aiming at the behaviors of countries and governments in the cultural field.

\section{THE PRACTICE OF CULTURAL GOVERNANCE IN}

\section{DEHONG PREFECTURE}

Dehong Dai and Jingpo Autonomous Prefecture is located on the frontier of southwest China having frontiers with Myanmar. The population of minority in the state accounts for $48.1 \%$. It is a It is the frontier of opening to the outside world. It is the frontier of Yunnan opening to the outside world with two first-class ports called Ruili and Wanding, and two provincial ports called Zhangfeng and Yingjiang. In January 2015 when visiting Yunnan province President Xi Jinping put forward "three positioning" requirements for the development of Yunnan province, one of which stressed that Yunnan need to become a radiation center facing southeast Asia and South Asia for the cultural exchange between Yunnan and southeast Asian countries. In this background, Dehong prefecture actively strengthens cultural exchanges with the states along the silk road and continuously innovate the way of external exchange in effort to achieve the long-term goal of political mutual trust and cultural exchange with the countries along the line of "the Belt and Road Initiatives".

\section{A.Improving the Function of Public Cultural Services in}

\section{Frontier Areas and Building a Common Cultural}

\section{Homeland for Cross-Border Ethnic Groups}

Art communication should be regarded as the leader. For a long time, Dehong prefecture takes the inheritance, protection and utilization of cross-border ethnic culture as a breakthrough, and the official and non-governmental cultural exchanges as supporting, puts great effort into the state-level development of "the construction of the digital culture corridor in frontier" . It has set up various kinds of festivals and seminars such as the annual China-Myanmar border trade exhibitions, China-Myanmar Pawkphaw Carnival, Jingpo Nationality International Munao Festival, Dai international water carnival, Dai international seminar, Jingpo culture international seminar, for the purpose of developing the cultural exchanges with the neighboring countries including Myanmar, Vietnam and Thailand, as well as deepening the understanding of Yunnan . 
In 2009, Dehong prefecture established the first Jiegao Port Book Library featuring books reading, loaning, selling and training services. By holding popular activities such as literary and artistic exhibitions, cultural lectures, cultural seminars and reading activities of middle school and primary school students it has attracted more and more China-Myanmar residents and foreign businessmen to come to the book library. In addition, through the realization of the full coverage of the radio and television in border area, the establishment of the newspaper in Myanmar, the construction of the network media communications capability, the exhibition of cultural exchange activities, such as China- Myanmar Sepa Takraw Competition, ethnic boxing, broad swordplay, cudgel play Dehong prefecture has set up a cultural homeland for the cross border nationalities.

\section{B.Building a Friendly Foundation for the Generation of}

\section{Cross-Border Ethnic Groups in the future}

Strengthening the external communication between education and civil society is an important part of the foreign cultural exchange in Dehong prefecture, such as improving conditions of border schools and port schools, continuously exploring to establish foreign personnel student status management, promoting teacher training, the entry and exit system of "student card" with green channel, etc. The students from Myanmar can be admitted to the nearest obligation education and participate in the entrance examination in Dezhong prefecture, enjoying education preferential policies, nutrition improvement program, and difficult student support fund. Besides, there are a lot of woman civil diplomacy activities, for instance, China-Myanmar woman community, work communication, project cooperation, Ruili women and children development center successfully registered in Myanmar, which is the first Chinese NGO registration in Myanmar.

\section{C.Ensuring the Religious Harmony}

\section{of Cross-Border Ethnic Areas}

Religious communication is a part of work of cultural exchange in border ethnic areas. The religious exchanges between China and Myanmar have been very close since ancient times. South-Shangzuo Buddhism Dehong has a deep historical connection with Myanmar. Christianity and
Catholicism were also introduced from Myanmar. In recent years, Dehong, based on earnest implements of the party's religious policies, the legal management of the religious affairs and harmonious guarantee of religion, the exchanges of religious and cultural values among the two sides from the high level are actively promoted, strengthening the exchanges of foreign religions and mutual learning among civilization and making a positive contribution to the harmony and tranquility of the border and the friendly relations between China and Myanmar. In June 2013, in Dezhong The Buddhist Association of China donated the tooth relic to Myanmar. The Buddhist Association of China, monks from the Buddhist circle of China and Myanmar, representatives from the Buddhist circles of the two countries and over 3,000 religious people attended the ceremony, which deepened the mutual trust between the two countries and made a positive impact, opening a new chapter in the high-level exchanges between the two countries. Since 2011, monks from Myanmar have been invited to attend water-sprinkling festival blessing activities in Dehong. When spontaneous disaster occurs around the two sides, monks woud hold prayer events irregularly. Starting from 2016, training overseas monks have became a routine activity. A bodhi school was opened in Ruili. Young monks of the two countries had chance to learn and live together, which can teach the teenage monks to understand each other.

\section{PROBLEMS EXISTING IN THE PRACTICE OF}

\section{CUltural GovernanCE IN DEHONG PREFECTURE}

The foreign cultural exchange activities carried out in the context of the "The Belt And Road Initiatives" are undoubtedly aimed at the cultural construction and development goals set by the state. Because of the high importance attached by the government, outstanding achievements have been made. However, from the perspective of cultural governance effectiveness, there are still some problems such as unclear governance ideas, undiversified subjects, lack of innovative methods in communication, and neglect of the role of national cultural traditions.

\section{A.The Need of clarifying the idea of cultural governance}

How to play the advantages of similar history, close relationship and culture for Dehong and South Asia and southeast Asian countries is always a problem for governments 
at all levels. In view of that fact that the government at all levels do not know enough about the importance and necessity of cultural exchanges, the combination of information, policy and the resources has not been completely formed and clear ideas have not been developed. Therefore, it is impossible to formulate relevant development plans, which will result in a long-term shortage for systematic and institutionalized policy measures to support the cultural exchange of the cross border ethnic area. Furthermore, because of some limits by the international diplomatic level it is difficult to upgrade the scale and the international influence of the various joint platforms and cooperation mechanisms.

\section{B.The Need of Diversifying the Subject of Cultural}

\section{Communication}

Government, enterprises, non-governmental organizations and individuals can become the main body of cultural governance in the process of promoting the development of cultural innovation. However, at the present stage, the main body of the cultural construction of Dehong prefecture is still unitary and the enthusiasm, initiative and creativity of the people at all levels in the development of cultural reform have not been fully mobilized. In the aspect of foreign cultural exchange, Dehong is still mainly engaged in official exchanges. In addition to a small number of intermarriage and border trade, there is little communication between the two countries. As an important force in external communication, enterprises are also one of the subjects in cultural governance. But it is the fact that companies have limited ability to carry out public diplomacy alone. The cooperation and resources among relevant government departments, the relationship of political parties, media and non-governmental organizations have not been fully utilized, and they have not formed an interconnected and mutually supportive situation[1].

\section{C.The Need of Improving the way of cultural governance}

There still exist some problems in the diversity of deep cultural exchanges, low level and insufficient development of cooperative brands. The research on the communication mode of traditional culture such as rural culture is not thorough enough and the professional packaging planning for intangible cultural heritage resources and external communication platforms are in lack of careful consideration. Besides, the narrow channel of communication as well as the shortage of publicity and characteristics of culture make it difficult for Yunnan culture to be transmitted. The form of foreign cultural exchange is not rich enough, and large-scale cultural exchange programs such as China-Myanmar Pawkphaw Carnival, Jingpo Nationality International Munao Festival, Dai international water carnival, Dai international seminar, Jingpo culture international seminar, still need to be carried out actively. In addition there is a lack of multi-level and multi-dimensional cooperation in the fields of literature, art, radio, film, television, press and publishing. Accordingly, it is difficult to spread the excellent culture of Yunnan province in a comprehensive way. It is seen that the policy makers and executives in ethnic areas do not pay attention to the emergence of minority cultural elements in public facilities, such as neglecting the use of minority languages in books, newspapers ,periodicals, movies, television, and other cultural products and services, and the urban construction and residence in ethnic areas have not reflected national characteristics.

\section{D.The Need of Strengthening the Role of Ethnic}

\section{Traditional Culture in Cultural Governance}

The ethnic customs in cross-border ethnic areas are the habits formed in the folk production and social life, which are the products of the accumulation of historical development and a mode of life that people abide by. Village rules are the norm and behavior regulation of the local group in the long life. The ethnic customs in frontier areas have certain moral restraints, stipulating and hinting people in all aspects, such as life and death, food and clothing, etc., telling them what should be done and what should not be done. Through investigation, we have seen that village rules have the function of regulating social members' behavior and social order. However, due to the lack of norms and guidance from local government policies, it is bound to affect its implementation effect and the role of behavior regulation to social members.

\section{REFLECTION ON THE PRACTICE OF CULTURAL}

\section{GOVERNANCE IN CROSS-BORDER ETHNIC AREAS}

The concrete practices of the cultural construction of cross-border ethnic groups show that cultural governance is a process of long-term and hard work. According to the general 
goal of perfecting the modern system of socialist modernization, the cultural governance of the frontier people in Yunnan province need to be paid more attention in many aspects.

\section{A.Formulating the Development Plan of Cultural}

\section{Construction}

According to the historical source superiority among Dehong and south Asian countries and southeast Asian countries with favorable geographical, human, cultural and commercial condition, it is better to come up with some relevant development plans. The specific implementation plan of promoting cultural construction need to be formulated according to its own advantages. It is necessary to strengthening the organizational implementation, supervision and inspection of the planning, guide the attention of all regions and enterprises, formulate and perfect the industry development plan, and promote the orderly and scientific development of foreign cultural trade.

\section{B.Playing the Role of NGO Cultural Exchanges}

As an effective complement to the government, various non-governmental organizations play an important role in social governance, which can promote scientific and technological progress and promote the development of public welfare undertakings. Non-governmental organizations, such as public welfare organizations, women's and children's organizations and foundations, have a certain role in promoting the management of the government. The NGO has a unique advantage in the governance of the grassroots. It can effectively integrate the resources, and become supplement to the laws and administration, raise the public's social responsibility awareness, uphold the moral code, promote service and volunteer spirit, expand grassroots democracy, and open up the primary governance space. Cultural and arts associations, literary and art organizations and other performing activities, while inheriting the folk art, are also combined with national policies to further satisfy the daily needs of the People's spiritual life and promote education effect, thus providing favorable conditions for the smooth operation of the government. Interaction of folk culture, as a hidden force, is of great significance in promoting harmonious relations among ethnic groups and states.

\section{C.Innovating Ways and Means of Cultural Governance}

It's a very important to promote the culture of ideas in basic level. We can use the media, television, newspapers, etc as platforms, with a very pleasant and accessible way, such as the allegro of party's propaganda, the news in local minority language, the policies of benefit people, the national music, and take over rural position by active and positive thoughts and culture .It can help to enrich the people's lives, and spread advanced culture, as well as drive the cultural enthusiasm to the local people, slowly building changes in people's ideas, actions and their lives.

\section{D.Giving Play to the Governance Function of National}

\section{Traditional Culture}

The customs in the cross-border ethnic areas mostly advocate the traditional virtues such as active kindness, respecting the old and loving the young, diligence and honesty, loyalty and filial piety, etc. There are many rules and customs that regulate social morality and benefit the people's physical and mental health, which raise the folk customs and etiquette habits of the cross-border ethnic areas to the village rules that are close to the people's life. Through the way of villagers' self-government, it can not only guide the people to get along with each other, help each other, inherit good moral culture and ideas, but also regulate the behavior of the masses to a certain extent, maintain a harmonious and stable social environment, and become the auxiliary power of government management and save the cost of it. The elders and leaders in the cross-boundary ethnic regions also play an auxiliary role in local governance and can help to deal with some disputes.

The religious belief in cross-border ethnic areas is more complex, and many religions coexist, while the religious culture is directly related to the stability of the popular people. Inheritance and evolution of religious culture has influence on thoughts and behavior of the people who believe it. Religious culture is a long existence in the people's life, they have accepted the influence of religious culture since childhood. Religious ceremony, taboo, etc., also have important influence on people's daily life and customs. It is of great practical significance to guide and educate believers to pursue the mainstream ideology and regulate their own behavior. 


\section{CONCLUSION}

The British sociologist Zygmunt Bauman said, "the idea of the culture," which was coined in the late 18th century as the abbreviation for managing human thought and behavior, "so the culture often contains another implication, which is turning the human being into the subject of easy governance, in other words, the culture is the meaning of governance. Through the empirical examination of the foreign cultural exchange activities in Dehongzhou, we can see that the problem of governance in the cultural field has been more and more concerned by the factwith the deepening of the reform of our country, how to manage it through culture governance, is the question that both theoretical researchers and practitioners should think about.

\section{ACKNOWLEDGMENTS}

Thanks to the counselors in government of Yunnan province office for the precious suggestions; Appreciation of Dehong Prefecture Party Committee Propaganda Department, Culture and Sports Bureau, Literature and Religion Bureau for providing support and help to this research paper.

\section{REFERENCES}

[1] [A] Bauman, Zygmunt. Liquid Life[M](Xu Chaoyou. Trans.) Nanjing, Jiangsu People's Publishing House. 2012:56.

[2] [B] Bennett,T,(1992).Putting policy into cultural studies. in L . Grossberg. C. Nelson \& P. Treichler(Eds) , Culrural Studies(pp.23-37).N .Y: Routledge.

[3] [C] Bennett, T.(2003).Culture and governmentality. In J. Z. Bratich, J. Packer, and C. McCarthy (Eds.), Foucault, Cultural Studies, and Governmentality(pp.47-63). Albany: State University of New York Press.

[4] [D] Bennett, Tony. "Civic Laboratories: Museums, Cultural Objecthood and the Governance of the Social." Cultura; Studies vol. 19, no. 5(2005):542.

[5] [E] Bennett, Tony. Culture and Society [M](Wang Jie, Qiang Donghong. Trans.) Guilin, Guangxi Normal University Press. 2007:163-197.

[6] [F] Chen Meilan. The cultural governance context of Taiwan's folk song creation in Taiwanese language. Journal of theory horizon.2011(4).

[7] [G] Han Meiqun. National Culture Governance: Position, Connotation, Characteristics and Path Innovation. Journal of Chongqing technology and business university(Social science edition). 2018(1):1-5.

[8] $[\mathrm{H}] \mathrm{Hu}$ Huilin. National Cultural Governance: New Dimension of Developing Cultural Industries. Journal of academic monthly. 2012(5).

[9] [1] Malinowski , Bronislaw Kaspar. A Scientific Theory of Culture[M](Fei Xiaotong.Trans.). Beijing, Central folk literature and art publishing house. 1987:14.

[10] [J] Wang Zhihong. Is Cultural Governance the Key Word?. Journal of Taiwan social study. 2011(82)

[11] [K] Wu Licai. Three Faces of Cultural Governance. Journal of central China normal university(Humanities and social sciences). 2014(1):58-68.
[12] [L] Wu Yanming. Govern "cultural governance": Fu Ke, Bennet and Wang Zhihong. Journal of Taiwan social study. 2011(8) : 171-204.

[13] [M] Xi Jinping. The CPC central committee's decision on comprehensively deepening reform of several major issues[N]. People's Daily. 2013(1):11-15.

[14] $[\mathrm{N}] \mathrm{Xu}$ Mingzhe. Construction of the Culture and the Management in Boarder Area. Dongjiang Journal.2016(4):2.

[15] [O] Xu Yichao. On Cultural Governance: A "New" Perspective in Cultural Studies. Journal of studies in culture \& art. 2014 (3) : 33-41

[16] [1] See resources: Work Report on Dehong Prefecture Culture Reform Based on the Characteristics of Humanistic Resources and the Strengthened Foundation of Communication among Nations 